\title{
J. S. Bach’ın Çello Süitlerine İlişskin Bir Literatür İncelemesi
}

\author{
EVIN ERDEN TOPOĞLU \\ evinerden@hotmail.com \\ ORCID ID: 0000-0002-6731-5790
}

Öz: J. S. Bachin eserleri el yazması veya kopya durumunda olup bu eserlerin bir kısmı kaybolmuştur. Bu durum, bestecinin ne istediğinin tam olarak bilinememesine neden olmakta ve eserlerinin yorumlanmasını daha da zorlaştırmaktadır. J. S. Bachin Çello Süitlerinin günümüze kadar ulaşan dört kopya el yazması bulunmaktadır. Bu eserlere ilişkin günümüze kadar ulaşmış otograf olan tek kaynak ise 5. süitin lavta transkripsiyonudur. Bu süitlerin otograflarmın kayıp olması nedeniyle, ne zaman ve ne sürede yazıldıkları ancak tahminlere dayanmaktadır. Hakkında sahip olunan bilgilerin kısıtl olması bir taraftan eserlerin yorumlanması konusunda belirsizliklere yol açsa da diğer taraftan zengin bir yorumlama anlayışı firsatı sunmuştur. Bu bağlamda, bu çalışmanın amacı barok dönem içerisinde ve günümüzde J. S. Bachin çello süitlerinin yerini irdeleyerek bu eserlere ilişkin literatürü incelemektir.

Anahtar kelimeler: J. S. Bach, Çello süitleri, El yazmaları.

\section{Giriş}

Johann Sebastian Bach kendisinden önce ve sonraki besteciler arasında köprü oluşturmuş, yaşamı süresince çok sayıda önemli eserler vermiş, yalnızca döneminin müziğini doruk noktasına ulaştırmakla kalmayıp müziği ile modern sanatlar üzerinde de etki yaratmış olan, gelmiş geçmiş en önemli bestecilerden biri olarak kabul edilmektedir. J. S. Bach’n en büyük temsilcilerinden olduğu, görkemli, süslü ve ağırbaşlı bir stili yansıtan "Barok Dönem” 17. ve 18. yüzyıllarda Alman ve Avusturya mimarisinde ortaya çıkmış, müzik alanında yaygınlaşmıştır. ${ }^{1}$ Barok müziğin genel özelliklerine 1600'lerden önce de rastlansa da, 1600-1750 yılları arasındaki süreç bestecilerin müziği nasıl şekillendireceklerine, nasıl bir yol izleyeceklerine karar verdikleri ve bunu bir gelenek haline getirdikleri dönem olması nedeniyle bu yılları kapsamaktadır. $^{2}$

\footnotetext{
* Dr. Öğr. Üyesi, Adnan Menderes Üniversitesi, Eğitim Fakültesi, Güzel Sanatlar Eğitimi Bölümü, Müzik Eğitimi Anabilim Dalı.

1 Lale Feridunoğlu, İz Bırakan Besteciler Yaşamları ve Yapıtları, İstanbul: İnkılap Kitabevi, 2005, s.16.

2 İlke Boran ve Kıvılcım Şenürkmez, Kültürel Tarih Işı̆̆ında Çoksesli Batı Müziği, İstanbul: Yapı Kredi Yayınları, 2015 , s.84.
} 
Barok müzikte, hepsi birbirine karışmış mistisizm, taşkınlık, karmaşıklık, süs, alegori, çarpıtma, doğaüstü ya da muhteşem olanı kullanma gibi üslupsal abartı söz konusudur. Barok dönem hareketi, çalkantıyı ve kuşkuyu temsil etmiştir. Bu dönem sürekli bas ve dört parçalı armoniye, eski kilise makamlarının unutulmasına, majör/ minör dizeleri ve bunlarla bağlantılı anahtarların pekişmesine, müziği vurgulu ölçü çizgilerine bölen ritmik düşüncelerin gelişmesine tanık olmuştur. ${ }^{3}$ Yaklaşık olarak 1600 yılından itibaren iki zamanlı olan nota değerlerine uzatma noktası, bağ veya üçleme sayıları sonradan eklenmiş ve pek çok şey seslendirme pratiğine bırakılmıştı. ${ }^{4}$ Barok dönem yorumcuları için besteci tarafından yazılmış bir yapıta doğaçlamalar eklemek bir gelenekti. Günümüzde müzikologlar, şefler ve yorumcular barok müzik yorumu ile ilgili araştırmalar yapmaktadırlar ancak bu uygulamalar yazılı kaynaklara dayanmadıkları için tahminlerde bulunmak oldukça zordur. ${ }^{5}$

Bach’n eserleri el yazması veya kopya durumunda olup bir kısmı kaybolmuştur. Müziğine ilişkin 20. yüzyılda karşımıza çıkan en önemli sorunlardan biri, performans pratiği konusudur. Eserlerine yönelik performans pratiğinin bazı detaylarına ulaşmak bugün mümkün değildir ve çalgılar, süsleme, renklendirme, dengeleme, ritim, tempo gibi kavramlar hakkında yalnızca tahminlerde bulunulabilir. Bach'ın zamanında yapılanı tekrarlayacak bir performansı yeniden yaratmak olanaksızdır. Solo yaylı çalgılar için yazdığı müzikler yaratıcılık, karmaşıklık ve zorluk bakımından aşılamamıştır. Bu bağlamda, çello süitlerinin bölümleri de son derece karmaşık ve zordur. $^{6}$

J. S. Bach solo çello için olan 6 çello süitini, Prens Leopold'un büyük desteğini almasının yanı sıra, provalara yeterli zaman ayırabildiği, harika müzisyenlerle bir arada olduğu Köthen Dönemi’nde yazmıştır. Bu dönem J. S. Bach için başka çalgısal eserler yazmış olması bakımından da oldukça verimli bir dönemdir ve bu dönemi bazı tarihçiler, Bach'ın en mutlu dönemlerinden biri olarak tanımlamaktadır.7 Bach'ın müziğinden oldukça etkilenen Köthen Prensi ona kendi sarayında şeflik teklif etmiş bunun üzerine Bach, Dük Willhem Ernst’e Weimar'daki görevinden ayrılmak istediğini söylemiş ve ardından bu sebeple hapse atılmıştır. Bach’ın çello süitlerini büyük ihtimalle cezaevindeyken tasarlamaya başladığ 1 ve cezaevinden çıktıktan sonra yaklaşık olarak 1720'de, çalgısal müziğe yoğunlaştığ 1 dönemde yazdığ ancak bazı süitlerin birbirinden ayrı zamanlarda yazıldığı daha sonra bu altı süitin bir araya getirilmiş olabileceği ihtimali de vardır. Dolayısıyla uzun sürede yazılmış olma ihtimali de söz konusudur. ${ }^{8}$ Weimer Dönemi ve onu izleyen Leipzig Döneminin aksine Köthen Dönemi’nin (1717-1723), Bach’ın yalnızca saray müziğinden sorumlu olması nedeniyle çalgısal eserlere yoğunlaştığı bir dönemdir bu nedenle

3 Harold Schonberg, Büyük Besteciler, çev., Ahmet Fethi Yıldırım. İstanbul: Doğan Egmont Yayıncılık, 2013, s.4243.

4 Ulrich Michels ve Gunter Vogel, Müzik Atlası, çev. Semih Uçar, İstanbul: Alfa Basım Yayım Dağıtım, 2013, s.273.

5 Boran ve Şenürkmez, Kültürel Tarih Işı̆̆ında Çoksesli Batı Müziği, s.117.

6 Schonberg, Büyük Besteciler, s.42-50.

7 Allen Winold, Bach's Cello Suites Analyses and Explorations Volume I: Text. Bloomingtom, Indianapolis: Indiana University Press, 2007, s.3.

8 Eric Siblin, The Cello Suites: J. S. Bach, Pablo Casals, and The Search For a Baroque Masterpiece. New York: Atlantic Monthly Press, 2009, s.27. 
bestecinin çalgısal müzikte çeşitli formlar deneme fırsatı olmuştur. Bach’ın bu süitleri kimin için yazdığı bilinmemekle birlikte Köthen saray şapelinin gambist ve çellisti Christian Ferdinand Abel veya Köthen sarayında çalışan çellist Christian Bernhard Linike için yazmış olabileceği düşünülmektedir. ${ }^{9}$

J. S. Bach’ın Çello Süitlerinin günümüze kadar ulaşan el yazmaları kopya durumda olup Kaynak A (A. Magdalena Bach), Kaynak B (J. P. Kellner), Kaynak C (Anonim Berlin), Kaynak D (Anonim Viyana) olarak kategorize edilmiştir. Araştırmacılar J. S. Bach'ın Çello süitlerinin kayıp durumda olan kendi el yazması ve yine kendi kopyası olan ikinci bir el yazması olduğunu tahmin etmektedirler. Bu eserlere ilişkin günümüze kadar ulaşmış otograf olan tek kaynak ise 5. süitin lavta transkripsiyonudur. Bu süitlerin otograflarının kayıp olması nedeniyle, ne zaman ve ne sürede yazıldıkları ancak tahminlere dayanmaktadir.

Bu süitler 19. yy'da yalnızca teknik çalışmalar olarak kullanılsa da yakın geçmişte konser eserleri olarak çalınmaktadır. ${ }^{10} \mathrm{~J}$. S. Bach’ın eğitim amacıyla yazıldığ 1 düşünülen solo çello süitleri, 20. yüzyılda efsanevi çellist Pablo Casals sayesinde unutulmaktan kurtularak popüler olmuştur. Bu eserler, 1824'teki ilk basılmış edisyonuna kadar neredeyse 100 yıldan daha fazla süre seslendirilmemiştir. Bestelenmesinden yaklaşık iki yüzyıl sonra yalnızca küçük bir grup profesyonel müzisyen ve Bach araştırmac1larının haberdar olduğu bu eserlerin konser salonlarında çalınmaya uygun eserler olmadıkları yalnızca teknik egzersizler oldukları ve çellonun solo bir çalgı olarak tek başına konser salonlarını doldurmaya yetecek denli önemli görülmemiştir. Uzun yıllar sonra Casals ilk kez seslendirmiş ve müzik dünyasını hayrete düşüren performansından sonra çello repertuarındaki önemi gittikçe artmıştır. ${ }^{11}$

Yo-Yo Ma, süitleri sergilediği altı kısa film yapmış, rock sanatçısı Sting birinci süitin prelude bölümünü gitarla çaldığı bir kısa film yapmıştır. Bu süitler özellikle Ingmar Bergman’ın filmlerinde yer almıştır. Ayrıca telefonlar için zil sesi olarak da çok sık kullanılmaktadır. Son yıllarda otantik müzik yaklaşımı da dahil, pek çok çalgı ile caz ve geleneksel Güney Afrika müzikleri olarak da yorumlanmıştır. 2007 yılında, yani eserler bestelendikten üç yüzyıl sonra, Rostropovich'in kaydı Itunes'da liste başı olarak kayda geçmiştir. ${ }^{12}$

J. S. Bach’ın çello süitleri yorumcular için teknik açıdan olduğu kadar yorumlama açısından da zengin bir kaynaktır. Hakkında sahip olunan bilgilerin az sayıda ve gizemli olması bir taraftan eserlerin yorumlanması konusunda belirsizliklere yol açsa da diğer taraftan zengin bir yorumlama anlayışı fırsatı sunmuştur. Bu bilgiler doğrultusunda, söz konusu eserlere ilişkin bir literatür incelemesinin önemli olduğu düşünülmektedir. Bu bağlamda, bu çalışmanın amacı barok dönem içerisinde ve gü-

9 Bettina Schwemer ve Doaglas Woodfull-Harisson, 6 Suites a Violoncello Solo senza Basso BWV 1007-1012. Kassel: Bärenreiter 2014, s.9.

10 Jungmook Lim, "A Perfomance Guide to J.S. Bach's Suite No. 5 For Violoncello Solo: The Interpretation of The Ornaments, Rhythm, Bowing and Phrasing, and Polyphonic Texture”, Doctor of Musical Arts Dissertation, University of Cincinnati, 2004, s.9.

11 Siblin, The Cello Suites, s.5-71.

12 Siblin, The Cello Suites, s.7-8. 
nümüzde J. S. Bach’’n çello süitlerinin yerini irdeleyerek bu eserlere ilişkin literatürü incelemektir. Literatüre bakıldığında, söz konusu eserlerin yorumlanmasına ilişkin araştırmalar olduğu gibi bu eserlerin yalnızca bir materyal olarak kullanıldı̆̆ farklı bilimsel amaçlar doğrultusunda gerçekleştirilmiş çalışmalar olduğu da görülmektedir.

\section{Eserlerin Yorumlanmasına İlişkin Literatür}

Karakelle, J. S. Bach’ın hayatı, müziği, yorumu ve stili, eserleri, çello için bestelediği 6 Solo Süitine ilişkin bilgiler vermiştir. Çalışmanın sonucunda, bu süitlerin çalıcıya teknik ve müzikal anlamda büyük katkı sağladığına vurgu yapılmıştır. ${ }^{13}$ Pridle, Barok prelude formunu J. S. Bach Çello Süitleri bağlamında tonal yapı, form ve motif yapısı açısından incelemiş, ${ }^{14}$ Markovic ise, armoni, form, melodi, ritim, artikülasyon bakımından karşılaştırmış, aralarındaki benzerlikleri ve farklılıkları ortaya koyarak, Pieter Wispelwey ve Daniel Muller-Schott'ın kayıtlarından da yararlanmış, modern ve barok çello ile yayları arasındaki farklılıkları incelemiş ve eserin yorumlanmasına ilişkin kendi görüşlerini detaylı şekilde ortaya koymuştur. ${ }^{15}$ Davis ise, barok çellonun en çarpıcı özellikleri hakkında bilgi vererek, J. S. Bach’n Çello Süitlerinin yorumlanmasında barok çellonun etkisini incelemiştir. Çalışmada, bu süitlerin yorumlanmasında barok çello ve modern çello arasındaki ilişki irdelenmiş, barok çello uzmanı Judith Davidoff, Myron Lutzke, William Monical ve Kenneth Slowik ile gerçekleştirilen görüşmelere de yer verilmiştir. Sonuç olarak, keman ailesinin barok dönemden bu yana şekillenmesinde estetik hazzın rol oynadığı, modern yorumcuların bu eserleri barok çello ile kendi otantik barok tınılarını yaratarak icra ettikleri sonuçlarına ulaşılmıştır. ${ }^{16}$

Lim'in çalışmasında, J. S. Bach'ın solo çello için yazılmış 5. süitinin süslemeler, ritim, yay, cümleleme ve polifoni yapısı açılarından yorumlanmasında rehber niteliğinde bir çalışma oluşturmak amaçlanmıştır. Çalışmada, J. S. Bach Çello Süitlerine ilişkin bilgiler verilerek, 5. Süitin yorumlanması ile ilgili örneklemelerde bulunulmuştur. Sonuç olarak, bu eserlerin yorumlanmasında bestecinin niyetinin anlaşılabilmesi adına, birçok edisyona göre el yazmalarının daha doğru kaynaklar olduğu vurgulanarak, yazarın kendi oluşturduğu açıklamalı bir J. S. Bach 5. Çello Süiti edisyonuna da yer verilmiştir. ${ }^{17}$ Dube ise, J. S. Bach'ın 5. Çello Süitinin prelude bölümünün üç farklı el yazmasını ve J. S. Bach’ın otografı olan lavta transkripsiyonunu karşılaştırmalı olarak inceleyerek bu bölümün yorumlanmasına ilişkin önerilerde bulunmuştur.

13 Tayfun Karakelle, “Johann Sebastian Bach Viyolonsel Süitlerinin İncelenmesi”, Yüksek Lisans Tezi, Gazi Üniversitesi. 2006.

14 Daniel E. Pridle, “The Form of The Preludes to Bach's Unaccompanied Cello Suites, Master Thesis, University of Massachusetts Amherst, 2011.

15 Nemanja Markovic, "The Interpretation of The Fifth Cello Suite BWV 1011 by Johann Sebastian Bach (16851750)", Master Thesis, Agder University, 2009.

16 Nathan J. Davis, "The Baroque Violoncello and the Unaccompanied Cello- Suites of J. S. Bach, B.W.V. 10071012”, Doctor of Philosophy Dissertation, New York University School of Education, Health, Nursing, and Arts Professions, 1986.

17 Jungmook Lim, “A Perfomance Guide to J.S. Bach’s Suite No. 5 For Violoncello Solo: The Interpretation of The Ornaments, Rhythm, Bowing and Phrasing, and Polyphonic Texture", Doctor of Musical Arts Dissertation, University of Cincinnati, 2004. 
Bu çalışmada, eserin el yazmaları, bestecinin kendi el yazması olan lavta transkripsiyonu ve Dimitri Markevich'in edisyonu, Fransız uvertürüne ilişkin bilgiler verilerek karşılaştırmalarda bulunulmuş ayrıca araştırmacının kendi yorumunu ortaya koyan bir edisyona da yer verilmiştir. ${ }^{18}$

Lawrence, J. S. Bach'ın Çello süitlerinin yazıldıkları döneme ve daha sonraki dönemlere etkisini araştırmıştır. Lawrence’ın araştırmasında bu süitlerin, aynı dönemde yazılan başka eserlerle kıyaslandıklarında, yaygın olarak daha çok sürekli bas ve eşlik çalgısı olarak kullanılan çellonun melodik ve armonik sınırlarını genişleten, hem klavsen ve org gibi klavyeli çalgıların hem de yaylı çalgıların özelliklerini bir araya getirerek solo bir çalgı için yazılmış olan, dönemini ve daha sonraki dönemleri etkileyecek olan başlıca eserler oldukları ileri sürülmüştür. ${ }^{19}$

Chambers, J. S. Bach'ın 5. Çello Süitinde kullanılan scordatura akortlama tekniği, bu tekniğin kökenini incelemiştir. Çalışmada, J. S. Bach’ın 5. Çello Süitinin yapısı, el yazmaları ve edisyonları hakkında bilgi verilerek bu eserin literatürde, basımı 1915’te olan Zoltan Kodaly'nin Solo Çello için sonatı (Op. 8)'na kadar scordatura akortlama tekniği ile yazılmış son eser olması bakımından önemine değinilmiştir. Çalışma sonucunda, eserin günümüzde scordatura akortlama ve normal akortlama olarak iki farklı şekilde de seslendirildiğine, ancak normal akortlamanın bestecinin niyetinden ve beğenisinden uzaklaştırdı̆̆ı vurgulanmıştır. ${ }^{20}$ Green, J. S. Bach 5. Çello Süitinin Anna Magdalena Bach ve Kellner el yazmalarını, 1824 Paris edisyonunu ve 1939 Schirmer edisyonunu karşılaştırarak incelememiştir. Çalışmada J. S. Bach’in kendi el yazması olan lavta transkripsiyonu ise, öncelikli olarak diğer edisyonlar arasındaki çelişkileri çözüme ulaştırmak için kullanılmıştır. Bu çalışma ile, Kellner’in el yazmasında önemli ölçüde daha çok tril ve bağ bakımından farklılıkların olduğu sonucuna varılmıştır. Anna Magdalena Bach'ın el yazması ile ilgili olarak ise, kopyalarken trilleri ihmal etmiş olma veya tril olup olmadığının icracının değerlendirmesine birakılmış olma ihtimali üzerinde durulmuştur. Kellner'in el yazmasında, orijinal scordatura edisyonunda "do-diyez"den kopyalanan çok sayıda "si natürel" niyetiyle yazılan "si-diyez"e rastlanmış olması nedeniyle bu edisyonun performans için düzenlenmemiş gibi göründüğü, belki de orga uyarlamak için düzenlendiği ve o nedenle gösterişli trillere daha çok önem verdiği, eğer org için uyarladıysa "sarabande” bölümünün uygun olmayacağını düşündüğü ya da o sayfanın kaybolmuş olduğu ihtimallerini ileri sürmüştür. ${ }^{21}$

Jarwis, J. S. Bach’ın Çello Süitlerinin gerçekten J. S. Bach tarafından yazılıp yazılmadığını incelemeyi amaçlamış ve bu çalışma ile Anna Magdalena Bach’ın, J. S. Bach’ın yazılarını ve nota yazılarını ayrıntılı bir şekilde karşılaştırılarak irdelemiş ve bu süit-

18 Michelle Clair Dube, "Prelude of Suite V for Cello Solo by J. S. Bach: Options For Performance", Doctor of Musical Arts Dissertation, Arizona University, 1993.

19 Meredith Lawrence, “The Influence of the Unaccompanied Bach Suites”, Proceedings of the National Conference on Undergraduate Research, Weber State University, 2012.

20 Mark Chambers, “The "Mistuned” Cello: Precursors to J. S. Bach's Suite V in C Minor for Unaccompanied Violoncello", 1996.

21 Curtis Green, "A Comparison of Selected Editions of Bach's Suie No. 5 in C”, Master of Music Thesis, Ball State University, 2009. 
lerin J. S. Bach tarafından yazılmamış olabileceğine işaret eden sonuçlar bulduğunu ileri sürmüştür. ${ }^{22}$ Hill, J. S. Bach 5. Çello Süitindeki ayrıntılı olarak bütün kaynaklar arasındaki farklılıklarını, artikülasyon ve süslemeleri incelemiştir. Sonuç olarak; her bir kaynağın önemi ve güvenirliği ile ilgili olarak, modern edisyonların hepsinin temel aldığı, çellistler ve editörler için önemli olan ve bu nedenle en sık kullanılan Anna Magdalena’nın kopyasının en az güvenilir olabileceği sonucuna ulaşmıştır. ${ }^{23}$

Kıran, J. S. Bach’ın Viyolonsel Süitlerinin yorumlanmasında farklı edisyonların etkilerini ortaya koymayı amaçlamıştır. Belirlenen amaç doğrultusunda, Afyon Kocatepe Üniversitesi Devlet Konservatuvarı, Anadolu Üniversitesi Devlet Konservatuvarı, Dokuz Eylül Üniversitesi Devlet Konservatuvarı, Mimar Sinan Üniversitesi Devlet Konservatuvarı ve Uludağ Üniversitesi Devlet Konservatuarı'nda görev alan ve gönüllü olarak çalışmaya katılmayı kabul eden, 6'sı lisans, 3’ü yüksek lisans ve 5’i sanatta yeterlik mezunu 14 viyolonsel sanatçısı/eğitmeni ile görüşmeler yapılmıştır. Katılımcıların 7'si kadın 7'si erkek olup, yaşları 24 ile 47 arasında değişmektedir. J. S. Bach'in 6 Viyolonsel Süitinden No. 1 Sol Majör Süit ile sinırlandırılan bu araştırmanın verileri, 17 soruluk bir görüşme formu ile toplanmıştır. Araştırmanın sonucunda; viyolonsel sanatçıları/eğitmenlerinin ortak bir edisyon kullanmadıklar1 ve eserin el yazmalarından nadiren faydalandıkları, edisyon tercihlerinde bağ ve parmak numaralarının kendi müzikal anlayışlarıyla örtüşmesine dikkat ettikleri ancak edisyona birebir bağlı kalmadıkları, zaman zaman değişiklikler yaptıkları, genel olarak eserin el yazmalarına sahip olmadıkları, el yazmalarındaki bağlardan yararlanma oranının yarı yarıya olduğu ve çoğunlukla bu bağları günümüz viyolonselinde icra etmek için uygun bulmadıkları, Barok dönem özelliklerini yansıtabilmek için otantik enstrüman kullanımının önemli olduğunu düşündükleri, çoğunlukla eseri kendilerine öğreten sanatçının/eğitmenin kullandığ 1 edisyonu temel aldıkları ve aynı şekilde kendilerinin de eseri öğrencilerine kendi parmak numaraları ve bağlarla öğrettikleri bilgisine ulaşılmıştır. ${ }^{24}$

Erden, J. S. Bach'ın 5. Çello Süitinin el yazmalarını, lavta transkripsiyonunu ve farklı edisyonlarını inceleyerek nota farklılıkları açısından karşılaştırmış ve Bach performansı konusunda uzman çellistlerin bu süitlerin el yazmalarına, farklı edisyonlarına ve 5. Süitin yorumlanmasına ilişkin görüşlerini ortaya koymuştur. J. S. Bach’n 5. Çello Süitin el yazması kopyalar olan A. Magdalena Bach, J. P. Kellner, Anonim Berlin, Anonim Viyana, J.S. Bach'ın otografi lavta transkripsiyonu ile Cotelle Edisyonu, Dörffel Edisyonu ve Dotzauer Edisyonu karşılaştırılmış, bu karşılaştırmalara ilişkin veriler doküman analizi formu ile toplanmıştır. Çalışma grubunu belirlenen ölçütlere uyan çello sanatçılarından/eğitimcilerinden Jirí Bárta, Anner Bylsma, Nicholas Deletaille, Roel Dieltiens, Leonid Gorokhov, Frans Helmerson, Ümit İşgörür, Laurence Lesser ve Alexander Rudin’in oluşturduğu çalışmada görüşmelere ilişkin veriler yarı

22 Martin W. B. Jarwis, “Did Johann Sebastian Bach write the six cello suites?", PhD Thesis, Faculty of Law Charles Darwin University, 2007.

23 Andrew John Hill, "A Critical Investigation and Re-Assessment of The Composition History of J. S. Bach's 5th Suite for Unaccompanied Violoncello BWV 1011”, PhD Thesis, The Open University, 2011.

24 Sezgi Sevi Kıran, “J. S. Bach’ın Viyolonsel Süitlerinin Yorumlarında Farklı Edisyonların Etkileri”, Doktora Tezi, Afyon Kocatepe Üniversitesi, 2012. 
yapılandırılmış görüşme formu yoluyla elde edilmiştir. Verilerin çözümlenmesinde doküman analizi ve içerik analizi uygulanan araştırmanın sonucunda, en çok hata içeren el yazmasının Kellner'in kopyası olduğu, çalışma grubunun tamamına yakınının eserin yorumlanmasında el yazmalarından yararlandıkları ve çoğunlukla Magdalena’nın el yazmasını tercih ettikleri, el yazmaları dışında edisyon kullanmadıkları, tamamına yakınının 5. Süiti scordatura akortlama ile çaldıkları, bu süitin yorumlanmasında dönemin stili ve müziği hakkında bilgi sahibi olarak özgün bir yorumun benimsenmesi gerektiğini düşündükleri ortaya konmuştur. ${ }^{25}$

Kramer, J. S. Bach Çello Süitlerindeki artikülasyonu dört farklı açıdan incelemeyi ve genel olarak modern icraya yönelik çıkarımlarda bulunmayı amaçlamıştır. Bu amaçlar doğrultusunda, çalıcıların ve teorisyenlerin ifade ettiği şekilde yay kullanımına ve retorik bir stilin oluşmasında rolü olan artikülasyona bakışı, çalgısal ve vokal stillerin yanı sıra, artikülasyon ile armoni, ölçü, nüans arasındaki ilişkiyi incelemiştir. Bunun yanı sıra çalışmada, bu süitlerin el yazmalarındaki artikülasyon işaretleri ile 19.yy ve 20.yy editörlerinin yorumu arasındaki ilişki, kopyaların doğruluğu ve modern yorumlama için yapılan çıkarımlar, Bach’ın yaylı çalgılar için yazdığı solo eserlerdeki artikülasyon işaretleri ve müzikal düşünüm arasındaki ilişki, artikülasyon ve barok çalgı tekniği ile Bach’ın bağ, ses aralığ 1 düzeni, armoni, süsleme, motif yapısı ve dans ritimleri arasındaki ilişki, Fransız ve İtalyan stilinde yazılmış bölümlerin artikülasyon bağlamındaki farklılıkları incelenmiştir. Çalışmanın soncunda, cümlelemenin 18.yy’a ait el yazmalarında daha çok, az sayıda nota ile özellikle de 4 bağlı notayı geçmeyecek şekilde kullanıldığı buna karşın 20.yy edisyonlarında daha çok legato bir anlayışın benimsenmesiyle mümkün olduğunca notaların bağlı kullanıldığı ortaya konmuştur. Bununla birlikte 18.yy kaynaklarında asimetrik bir yapısı olan üç bağlı bir ayrı $(3+1)$ veya bir ayrı üç bağlı $(1+3)$ nota kullanımına daha çok rastlanırken, 20.yy edisyonlarında simetrik yapıya sahip iki bağlı $(2+2)$ veya dört bağlı $(4+4)$ notaların daha çok kullanıldığı ileri sürülmüştür. ${ }^{26}$

Sung ve Fabian, ana akım performans ile tarihsel özelliklere uygun performanslar arasındaki ilişkiyi, J. S. Bach’ın 6. Çello Süitinin 20.yy’ın ikinci yarısındaki icrasında meydana gelen farklılıkları, zaman içerisinde bireysel profillerdeki gelişmeleri ve modanın, daha çok sosyal-kültürel eğilimlerin bu dönemdeki sanatçıların performansları üzerine olan etkilerini incelemiştir. Çalışmanın sonucunda; 90’lı yıllarda ana akım performanslar ile tarihsel özelliklere uygun performanslar arasındaki etkileşimin artmasıyla performans çeşitliliğinin de arttığ gözlenmiş ve bu durumun 20. yüzyılın son on yılında yaygınlaşan postmodern etkinin hâkim olmasından kaynaklanabileceği ileri sürülmüştür. Çalışmada belirtilen süreç içinde J. S. Bach Çello Süitlerini iki kez kayda almış olan Paul Tortelier (1961; 1982), János Starker (1963; 1992), Anner Bylsma (1979; 1992), Yo-Yo Ma (1983; 1995) ve Pieter Wispelwey (1990; 1998)'in kayıtları karşılaştırmalı olarak incelenmiştir. Detaylı bir tempo, ritmik esneklik, yay ve artikülasyon, vibrato ve portamento tablosu oluşturmak için

25 Evin Erden, “J. S. Bach’ın Çello Süitlerinin El Yazmaları ve Farklı Edisyonlarının Karşılaştırılması”, Sanatta Yeterlik Tezi, Yaşar Üniversitesi, 2015.

26 Laura Elizabeth Kramer, “Articulation in Johann Sebastian Bach's Six Suites for Violoncello Solo (BWV 10071012): History, Analysis and Performance”, Doctor of Musical Arts Dissertation, Cornell University, 1998. 
kayıtlar tekrar tekrar dinlenmiş, ses dosyalarının görüntülenmesi ve analizi "Sonic Visualiser” yazılım programı ile gerçekleştirilmiştir. Bu çalışma, bütün icracıların kendi çalma stillerinin bazı yönlerini muhafaza ettiklerini, bununla birlikte farklı eğilimlerin ortaya çıkmasına da katkı sağladıklarını ortaya koymuştur. ${ }^{27}$

\section{Eserin Araştırma Sürecinde Materyal Olarak Kullanımına İlişkin Literatür}

Sherwin ve Sajda’nın araştırması müzikal bir anomali sırasında uzman ve uzman olmayan denekler arasında fark olup olmadığını ortaya koymayı amaçlamıştır. Araştırmanın çalışma grubunu 3'ü kadın 2'si erkek olan 5 uzaman ve '2'si kadın, 3'ü erkek 5 uzman olmayan toplam 10 kişi oluşturmuştur. Uzman denekler konser çellistleri ile sınırlandırılmıştır. Deneyde Yo Yo Ma’nın J. S. Bach’nn 1. Çello Süitinin prelude bölümü kaydı üzerinde toplamda 140 ton değişikliği yapılmıştır. Tanımlanan sinirsel işaretlerle, müzikal bağlamda, uzmanlar ve uzman olmayanlar arasında farklılık olduğu, tonal değişimlerde uzman deneklerde somotosensorik (bedensel-duyusal) ve motor tepkilerin uzman olmayanlara göre daha çok örtüştüğü tespit edilmiştir. ${ }^{28}$

Bangert ve diğ., çalgı çalan müzisyenlerin uzmanlık sürecinde müzikal fikirlerinin nasıl oluştuğu, çift yönlü bilişsel teoriler olarak tanımlanan sezgi yoluyla keşfedilen (1.tip) ve bilinçli (2.tip) süreçler arasındaki ayrım incelenmiştir. Çellist Daniel Yeadon'ın durum çalışması, 2 yıl sürmüş ve veriler Yeadon'ın J. S. Bach Çello Süitleri’ne ilişkin görüşmeleri ile toplanmıştır. Analizler sonucunda 134 müzikal fikir sezgisel, yöntemsel, bilinçli veya tarihsel bilinçli performans olarak kategorize edilmiştir. Yöntemsel kararların, zamanla otomatik hale gelmiş olan ve önceki bilinçli kararlar olarak tanımlanan sezgisel sürecin altkümesi olduğu ileri sürülmüş ve tarihsel bilinçli performansın kategorileri tarihsel bilgi uygulamalarına özgü bilgileri kullanma ile açıklanmıştır. ${ }^{29}$

Hong, nüans ile performansçının kendine özgü zamanlaması arasındaki motor süreci yeniden incelemiş ve bu inceleme sürecinde J. S. Bach Do Majör Çello Süitinin sarabande bölümünün belirlenen 20 kaydının zamanlama ve nüans analizine yer vermiştir. Çalışmada, 20. yüzyıl kapsamında örneklem olarak alınan çellistlerin genellikle motor hareket ile zamanlama ve nüans arasındaki gerekli disiplini motor mantık yoluyla yaptıkları sonucuna ulaşılmıştır. ${ }^{30}$

Brothers, diziyi, melodik aralıkların nitelikleri ile ilişkilendirerek açıklamıştır. 6 çello süitinden seçilmiş 36 kısma uygulanan ilişkili ses analizi ile çözümlemeler yapmıștır. Çalışmanın sonucunda, belirli bestecilerin eserlerinde bu tarz bir doğal denge bulma eğiliminde olabileceği ve eserlerinin bir ölçüde karakterize edilmiş olabileceğine dikkat çekilmiştir. Bu çalışma ile J. S. Bach’ın eserlerindeki fraktal dizilimin incelenerek

27 Alistair Sung ve Dorottya Fabian, "Variety in Performance: A Comparative Analysis of Recorded Performances of Bach's Sixth Suite for Solo Cello from 1961 to 1998”, Empirical Musicology, 6/1 (2011): 20-42.

28 Jason Samuel Sherwin ve Paul Sajda, "Musical Experts Recruit Action-Related Neural Structures in Harmonic Anomaly Detection: Evidence For Embodied Cognition in Expertise". Brain and Cognition, 83/2 (2013): 190-202. 29 Daniel Bangert, Dorottya Fabian, Emery Schubert ve Daniel Yeadon, "Performing Solo Bach: A Case Study of musical decision-making", Musicee Scientioe, 18/1, (2014): 35-52.

30 Ju-Lee Hong, "Investigating Expressive Timing and Dynamics in Recorded Cello Performance. Society for Education", Music and Psychology Research, 31/3 (2003): 340-352. 
analiz edilmesi, bestecinin yaratıcılığını bu boyutuyla ortaya koymuştur. ${ }^{31}$

\section{Sonuç}

Bu çalışmanın amacı barok dönem içerisinde ve günümüzde J. S. Bach’n çello süitlerinin yerini irdeleyerek bu eserlere ilişkin literatürü incelemektir. J. S. Bach’ın eşliksiz çello için süitlerinin el yazmalarının kayıp olması, birbirinden farklı dört el yazması bulunması ve bu eserlerle ilgili bilginin yetersiz olması nedeniyle eserlerin günümüzde yorumlanması konusu yorumcular için oldukça önemli bir sorundur. Bu durum diğer yandan eserle ilgili zengin yorumlama fırsatını da beraberinde getirmiştir. Literatür incelendiğinde söz konusu eserlere ilişkin çalışmaların, eserin yorumlanmasına yönelik veya bu eserlerin bir materyal olarak kullanıldığg farklı bilimsel amaçlar doğrultusunda gerçekleştirilmiş araştırmalar olduğu görülmektedir. Eserlerin yorumlanmasına yönelik çalışmalar genel anlamda yorumcuların eserin yazıldı̆̆ 1 döneme ait tarihsel bilgi ve üslup bilgisi ile icracılık deneyimleri doğrultusunda öne sürdükleri teknik ve müzikal fikirleri içermektedir ve bunların sayısı oldukça azdır. Diğer yandan bu eserlerin bir materyal olarak kullanıldığı çalışmaların sayısı da yine oldukça azdır. J. S. Bach’ın çello süitleri kendi dönemi içerisinde oldukça modern eserlerdir ve daha sonraki dönemlerde olduğu gibi günümüzde de farklı yorumlamalarla tekrar tekrar ele alınması eserlerin önemini ortaya koymaktadır. Yazıldıktan sonra neredeyse iki yüzyıl unutulmuş olan bu süitler Pablo Casals ile romantik bir üslup kazanmış ve günümüzde oldukça farklı yorumları olmasının yanı sıra pek çok yorumcu eski dönem çalgılarıyla, yaylarıyla ve stili ile yüzünü otantik üsluba çevirmiştir. Bu bakımdan, 21. yy 'da el yazmaları yalnızca müzikologların başvurduğu kaynaklar olmaktan çıkıp yorumcuların da 20. yy edisyonları yerine öncelikle başvurdukları kaynaklar olmaya başlamışlardır. Bärenreiter, bu doğrultuda, içinde el yazmalarının ve bir adet yorumcunun özgün bağlarını ve yorumunu oluşturmasına imkan veren boş bir nota yazısının bulunduğu bir edisyon basmıştır. ${ }^{32} \mathrm{Bu}$ anlamda, J. S. Bach’n çello süitlerinin yorumlanması öncelikle bu eserlere ve yazıldıkları döneme ilişkin yeterli bilgiye sahip olmayı gerektirmektedir. Belirli bir bilgi düzeyine ulaşmanın yolu ise daha fazla bilimsel çalışmadan geçmektedir. Sonuç olarak, söz konusu eserlerin el yazmalarına, eserlerin yazıldığ 1 dönemin üslubuna ve Bach yorumculuğuna yönelik bilimsel çalışmaların sayısının artmasının, bu konuda bir yandan yorumculara kaynak oluşturacağı diğer yandan daha zengin ve özgün yorumların ortaya çıkmasına yardımcı olacağı düşünülmektedir.

\section{Kaynakça}

Bangert, Daniel, Dorottoya Fabian, Emery Schubert ve Daniel Yeadon. "Performing

Solo Bach: A Case Study of Musical Decision-making”. Musicoe Scientioe. 18/1 (2014): 35-52.

Boran, İlke ve Kıvılcım Şenürkmez. Kültürel Tarih Işı̆̆ında Çoksesli Batı Müzĭği. İstanbul: Yapı Kredi Yayınları, 2015.

31 Harlan J. Brothers, "Intervallic Scaling in The Bach Cello Suites", World Scientific, 17/4 (2009): 537-545. 32 Bettina Schwemer, Doaglas Woodfull Harisson, 6 Suites a Violoncello Solo senza Basso BWV 1007-1012. 
Brothers, Harlan J. "Intervallic Scaling in The Bach Cello Suites". World Scientific. 17/4 (2009): 537-545.

Chambers, Mark. "The "Mistuned” Cello: Precursors to J. S. Bach's Suite V in C Minor for Unaccompanied Violoncello”. 1996.

Davis, Nathan J. "The Baroque Violoncello and The Unaccompanied Cello- Suites of J. S. Bach, B.W.V. 1007-1012”. Doctor of Philosophy Dissertation. New York University School of Education, Health, Nursing, and Arts Professions, 1986.

Dube, Michelle Clair. "Prelude of Suite V For Cello Solo By J. S. Bach: Options For Performance". Doctor of Musical Arts Dissertation. Arizona University, 1993.

Erden, Evin. “J. S. Bach’n Çello Süitlerinin El Yazmaları ve Farklı Edisyonlarının Karşılaştırılması”. Sanatta Yeterlik Tezi. Yaşar Üniversitesi, 2015.

Feridunoğlu, Lale. İz Bırakan Besteciler Yaşamları ve Yapıtları. İstanbul: İnkılap Kitabevi, 2005.

Green, Curtis. “A Comparison of Selected Editions of Bach's Suite No. 5 in C”. Master of Music Thesis. Ball State University, 2009.

Hill, Andrew John. "A Critical Investigation and Re-Assessment of The Composition History of J. S. Bach's 5th Suite for Unaccompanied Violoncello BWV 1011". PhD Thesis. The Open University, 2011.

Hong, Ju-Lee. "Investigating Expressive Timing and Dynamics in Recorded Cello Performance. Society for Education". Music and Psychology Research. 31/3 (2003): 340-352.

Jarwis, Martin W. B. “Did Johann Sebastian Bach Write The Six Cello Suites?”. PhD Thesis. Faculty of Law Charles Darwin University, 2007.

Karakelle, Tayfun. "Johann Sebastian Bach Viyolonsel Süitlerinin İncelenmesi”. Yüksek Lisans Tezi. Gazi Üniversitesi, 2006.

Kıran, Sezgi Sevi. "J. S. Bach’’n Viyolonsel Süitlerinin Yorumlarında Farklı Edisyonların Etkileri”, Sanatta Yeterlik Tezi. Afyon Kocatepe Üniversitesi, 2012.

Kramer, Laura Elizabeth. "Articulation in Johann Sebastian Bach's Six Suites for Violoncello Solo (BWV 1007-1012): History, Analysis and Performance". Doctor of Musical Arts Dissertation. Cornell University, 1998.

Lawrence, Meredith. “The Influence of the Unaccompanied Bach Suites”. Proceedings of the National Conference On Undergraduate Research. Weber State University, 2012 .

Lim, Jungmook. “A Perfomance Guide to J.S. Bach's Suite No. 5 For Violoncello Solo: The Interpretation of The Ornaments, Rhythm, Bowing and Phrasing, and Polyphonic Texture". Doctor of Musical Arts Dissertation. University of Cincinnati, 2004.

Markovic, Nemanja. "The Interpretation of The Fifth Cello Suite BWV 1011 by Johann Sebastian Bach (1685-1750). Master Thesis. Agder University, 2009.

Michels, Ulrich ve Gunter Vogel. Müzik Atlası. Çev. Semih Uçar. İstanbul: Alfa Basım Yayım Dağıtım, 2013.

Pridle, Daniel E. “The Form of The Preludes To Bach's Unaccompanied Cello Suites”. Master Thesis. University of Massachusetts Amherst, 2011. 
Schonberg, Harold. Büyük Besteciler. Çev., Ahmet Fethi Yıldırım. İstanbul: Doğan Egmont Yayıncilık, 2013.

Schwemer, Bettina ve Doaglas Woodfull-Harisson. 6 Suites a Violoncello Solo senza Basso BWV 1007-1012. Kassel: Bärenreiter, 2014.

Sherwin, Jason Samuel ve Paul Sajda. "Musical Experts Recruit Action-Related Neural Structures in Harmonic Anomaly Detection: Evidence For Embodied Cognition in Expertise". Brain and Cognition, 83/2 (2013): 190-202.

Siblin, Eric. The Cello Suites: J. S. Bach, Pablo Casals and The Search for a Baroque Masterpiece. New York: Atlantic Monthly Press, 2009.

Sung, Alistair ve Dorottya Fabian. "Variety in Performance: A Comparative Analysis of Recorded Performances of Bach's Sixth Suite for Solo Cello from 1961 to 1998". Empirical Musicology. 6/1 (2011): 20-42.

Winold, Allen. Bach's Cello Suites Analyses and Explorations Volume I: Text. Bloomingtom, Indianapolis: Indiana University Press, 2007. 


\title{
A Literature Review of J. S. Bach's Cello Suites
}

\author{
EVIN ERDEN TOPOĞLU
}

Abstract: The works of J. S. Bach are autographs or copies and some of them are lost. In this sense it is much more difficult for performers to know what the composer exactly wants. There are four manuscripts of J.S. Bach Cello Suites that has survived. The only source that has been reached to the present day is the autograph of the 5th suite's lute transcription. Due to the missing autographs of these suites, when and for how long they were written is based on estimates. Limited and mysterious knowledge of these works cause uncertainty about the interpretation, but on the other hand, it offered a substantial sense of interpretation. In this sense, the aim of this study is to examine the literature about the role of the J. S. Bach cello suites in the Baroque period and in the present.

Keywords: J. S. Bach, Cello suites, Manuscripts. 